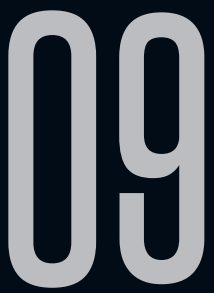

\title{
ENTENDENDO O PRESENTE PELO PASSADO: O STEAMPUNK DE A ALCOVA DA MORTE COMO RESGATE DA TRADIÇÃO DA FICÇÃO CIENTÍFICA BRASILEIRA
}

Alexander Meireles da Silva (UFG-RC)

Recebido em 05 nov 2019. Aprovado em 22 mar 2020.
Alexander Meireles da Silva é Doutor em Literatura Comparada pela Universidade Federal do Rio de Janeiro (UFRJ-2008). Desde 2009 atua como Professor Associado da Universidade Federal de Goiás - Regional Catalão (UFG-RC). Atua na Graduação da Unidade Acadêmica Especial de Letras e Linguística e no Programa de PósGraduação em Estudos da Linguagem da UFG-RC. Autor do livro Literatura Inglesa para Brasileiros: curso completo de literatura e cultura inglesa para estudantes brasileiros (2005) e organizador dos livros Tessituras Literárias: cultura, identidade e outras artes (2017) e Estudos do Gótico (2017). É membro fundador dos Grupos de Pesquisa Estudos Do Gótico (CNPq) e Nós Do Insólito: Vertentes Da Ficção, Da Teoria E Da Crítica (CNPq) Suas pesquisas se concentram na área da Literatura Fantástica e suas vertentes. É criador de conteúdo do blog Fantasticursos (www.fantasticursos.com) e do canal do YouTube Fantasticursos (youtube.com/fantasticursos), onde oferece conteúdo, cursos e consultoria sobre o Fantástico na Literatura e no Cinema nas vertentes da Fantasia, Gótico, Horror e Ficção Científica.

Lattes: http://lattes.cnpq.br/8325920517508979

E-mail: prof.alexms@gmail.com 
Resumo: Apresentando narrativas normalmente ambientadas no passado e que incorporam releituras tecnológicas e estéticas do século $X X$ no imaginário do século XIX, o steampunk vem conquistando relevância na Ficção Científica brasileira do século XXI promovendo o diálogo não apenas com as raízes literárias de sua ascensão no Brasil na segunda metade do século XIX, mas também com a problemática, ainda atual, quanto a configuração desta vertente romanesca dentro do cenário da literatura fantástica nacional. Neste quadro, após apresentar um breve panorama da história da ficção científica em nosso país iremos abordar a produção literária steampunk brasileira com ênfase no romance $A$ alcova da morte (2017) de forma a demonstrar como a obra de Enéias Tavares, Nikelen Witter e A. Z. Cordenonsi e outras produções fazem uso de diferentes elementos e estruturas narrativas que subvertem o gênero Ficção Científica no Brasil ao mesmo tempo em que se coloca como uma metáfora de um país onde o progresso científico não promoveu impactos positivos na qualidade de vida da sua população, afetando assim uma instalação mais aprofundada e disseminação da ficção científica na Literatura do início do século $X X$ em nossas terras.

Palavras-chave: Fantástico; Ficção Científica Brasileira; Steampunk.

Abstract: Presenting narratives normally set in the past and that incorporate twentieth-century technological and esthetic rereadings in the imaginary of nineteenth century, Steampunk has been acquiring relevance in twenty-first century Brazilian Science Fiction promoting a dialogue not only with the literary roots of its rise in Brazil during the second half of nineteenth century, but also with the problematic concerning the manifestation of this expression of fantastic mode within the scene of Brazilian Fantastic Literature. In this sense, after 
presenting a brief overview of Science Fiction history in our country we will approach Brazilian steampunk literary production with emphasis on the novel $A$ alcova da morte (2017) in order to demonstrating how this work by Enéias Tavares, Nikelen Witter and A. Z. Cordenonsi and other productions use different elements and narrative structures that subvert the Science Fiction genre in Brazil at the same time that acts as a metaphor of a country in which scientific progress did not promote positive impact on population life quality, affecting thus a deeper settlement and dissemination of Science Fiction in Brazilian Literature in early twentieth century.

Keywords: Fantastic; Brazilian Science Fiction; Steampunk.

A partir de um breve panorama da produção literária steampunk brasileira, com ênfase no romance $A$ alcova da morte (2017), de Enéias Tavares, Nikelen Witter e A. Z. Cordenonsi, este artigo tem como objetivo analisar como o subgênero conhecido como Steampunk vem ganhando relevância na Literatura Brasileira e, mais especificamente, na tradição da literatura fantástica brasileira, se colocando como um instrumento por meio do qual é possível refletir não apenas sobre o processo de surgimento da ficção científica no contexto histórico-cultural da segunda metade do século dezenove, mas também sobre a problemática, ainda atual, quanto a configuração desta vertente romanesca dentro do cenário da literatura fantástica nacional. ${ }^{1}$ Neste quadro, buscaremos demonstrar especificamente como o steampunk brasileiro em $A$ alcova da morte e outras obras fazem uso de diferentes elementos e estruturas narrativas que subvertem o gênero Ficção Científica

1 Neste artigo tomaremos a Ficção Científica como uma expressão do modo fantástico, conforme preconizado por Remo Ceserani em O fantástico (2006). 
ao mesmo tempo em que se colocam como uma metáfora de um país onde o progresso científico não promoveu impactos positivos na qualidade de vida da sua população, afetando assim uma maior instalação e disseminação da ficção científica na Literatura do início do século $X X$ em nossas terras.

Em seus momentos iniciais, quando o termo foi cunhado em fins dos anos oitenta do século passado, o steampunk surgiu vinculado a outro subgênero da ficção cientifica que também se disseminaria na mesma década: o Cyberpunk. Batizado a partir de um conto do escritor Bruce Bethke publicado em novembro de 1983 na revista Amazing Science fiction e popularizado pelo editor Gardner Dozois ao se referir à produção literária de um grupo de escritores da época (FERNANDES, 2006, p.52-53), o cyberpunk tem seus marcos iniciais no romance Neuromancer (1984), de William Gibson, e na coletânea de contos Mirrorshades (1986), organizada por Bruce Sterling.

Caracterizado pela descrição de sociedades futuras nas quais a alta evolução tecnológica, incorporada até o nível do corpo humano, não trouxe melhorias para a baixa qualidade de vida da maior parte da população - uma ideia resumida na oposição "High Tech X Low Life" esse subgênero da ficção científica se tornou uma das principais expressões literárias do ambiente finissecular ao capturar o ceticismo e pessimismo vigente no período quanto aos rumos do futuro. Foi essa popularização e significância do cyberpunk, principalmente em abordar temas relevantes da sociedade a partir de outro contexto histórico, que inspirou o escritor Kevin Wayne Jeter, em uma carta publicada em 1987 na revista Locus, a explicar que o seu romance Morlock Night (1979), assim como também a 
obra The Anubis Gate (1983), de Tim Powers, entre outros exemplos, eram o que se poderia chamar de "steampunk" (PEGORARO, 2014, p.3-4). Mas o que é exatamente o steampunk?

Definida por John Clute e Peter Nicholls como uma narrativa "cujos elementos de ficção científica acontecem em um cenário do século 19" (CLUTE; NICHOLLS, 1993, p.1161 - tradução dos autores), ${ }^{2}$ o steampunk se diferencia do cyberpunk, em um primeiro momento, pelo elemento Tempo. No cyberpunk, em essência, "cyber" designa a força motriz do mundo distópico projetado no futuro e alicerçado nos sistemas de informação digitais e na estreita relação homemmáquina. O "punk", por sua vez, remete a contestação e rebeldia contra o status quo. Já no steampunk, "steam" designa a força motriz do mundo retratado, projetado normalmente no passado e alicerçado no vapor e na estreita relação homem-máquina. Destacase aqui que, diferente do cyberpunk em que o tom distópico é predominante, o steampunk apresenta contestações ao lugar da tecnologia e do discurso racionalista na sociedade, propondo, por vezes, alternativas sustentáveis ao sistema. A palavra "punk", da mesma forma, remete a contestação e rebeldia contra o status quo. Assim sendo, o steampunk nasce como um subgênero da ficção científica que incorpora releituras tecnológicas e estéticas do século XX no imaginário do século XIX.

Destaca-se que, principalmente no século XXI, além da sua existência enquanto expressão da literatura fantástica o steampunk também se expressa como uma "cena" (STRAW, 2006), ou seja, uma "caracterização das expressões culturais juvenis contemporâneas, marcadas por um estilo próprio e com visibilidade social."

2 "[...] whose SF elements take place against a 19th-century background." 
(HERSCHMANN, PEGORARO, FERNANDES, 2013, p.9). Neste sentido, como destaca Éverly Pegoraro (2014) o Brasil conta com crescente número de entusiastas por esta cultura urbana. Os steamers - como são conhecidos - se organizam em células denominadas como "lojas" (derivado da Maçonaria no sentido de ajuda mútua) com o propósito de divulgação das atividades desta comunidade.

A vinculação entre cyberpunk e steampunk também se faz sentir nos nomes principais que disseminaram essas narrativas em seus momentos iniciais. Assim como fizeram respectivamente em Neuromancer e Mirrorshades, apontando os caminhos do cyberpunk, William Gibson e Bruce Sterling também moldaram o steampunk ao escreverem, em conjunto, o romance A máquina diferencial (1990), considerado um dos marcos desse subgênero (NEVINS, 2008, p.3).

A obra retrata o impacto que a invenção da máquina diferencial de Charles Baggage exerceu sobre a Inglaterra vitoriana de uma realidade alternativa, levando o país a conquistas tecnológicas movidas pela energia do vapor. Charles Baggage, de fato um personagem histórico, foi um engenheiro e matemático que concebeu a ideia de uma calculadora mecânica programável como um computador e dotada de impressora. Todavia, a limitação tecnológica do século XIX não tornou possível a sua construção em nossa realidade. Já no mundo steampunk de William Gibson e Bruce Sterling a Máquina, como o dispositivo de Baggage é conhecido, permitiu que a Inglaterra se tornasse uma tecnocracia, vindo a exercer influência em regiões distantes como o Japão e provocando a divisão dos Estados Unidos. Na esfera doméstica, o elemento punk se revela, dentre outras formas, na supressão violenta aos luditas, críticos da tecnologia da Inglaterra de seu tempo. 
A enorme predominância da utilização da Inglaterra vitoriana como ambientação das obras steampunk revela outra dimensão da categoria Tempo que diferencia o steampunk do cyberpunk e que se conecta diretamente com a questão do retrofuturismo enquanto termo que visa revisitar o passado por meio do uso da alta tecnologia possível para aquele cenário, mas focando no aspecto social ocasionado por aquela tecnologia. Dentro deste cenário, o cyberpunk captura as imperfeições do hoje e os extrapola em um amanhã concebido pelo escritor ou escritora. Assim, é a partir do futuro distópico imaginado que se adverte sobre o presente, o que expõe a natureza do cyberpunk como criação única da Literatura. Já o steampunk, quando bem desenvolvido respeitando-se o seu zeitgeist, captura as imperfeições do ontem e os manipula no próprio ontem, provocando um diálogo entre História e Literatura expresso no uso do histórico como matéria prima para a representação de sua visão crítica da sociedade. A compreensão desse processo evidencia, portanto, que a Inglaterra da segunda metade do século XIX, explorado pelo steampunk, apresenta elementos socioculturais, políticos e econômicos semelhantes às sociedades futuras imaginadas nas obras cyberpunk.

Falar da Inglaterra vitoriana no plano externo é relembrar a extensão do domínio territorial do Império britânico no mundo em meados do século XIX, englobando, dentre outros países, Canadá, Austrália, Hong Kong, Nova Zelândia, Ilhas caribenhas, Índia, África do Sul, Egito e Nigéria. Essa amplitude de poder justificava o orgulho do administrador real Sir George Macartney expressado na frase: "O sol nunca se põe no Império Britânico" (MACARTNEY Apud KENNY, 2006, p.72). Ou seja, como era salientado pelos entusiastas 
do expansionismo inglês à época, sempre havia alguma parte do planeta dominado pela Inglaterra iluminado não apenas pelo sol, mas também pelo discurso progressista britânico. Conforme destaca Eric Hobsbawm sobre a questão: "No final do século dezenove, o sucesso obtido [...] foi notável [...] pela monarquia britânica [a conquista de] um quarto da superfície do globo" (HOBSBAWM, 1988, p.111). Alicerçada em uma marinha de guerra de poderio bélico incontestável, liderança absoluta na indústria e no comércio, a Pax Britannica durante o reinado da Rainha Vitória (1837-1901) foi construída sob a firme convicção de que "o desenvolvimento se transformasse num mundo onde os 'avançados' dominariam os 'atrasados'" (HOBSBAWM, 1988, p.87), ressoando um discurso que refletia uma visão corrompida das ideias defendidas pelo naturalista Charles Darwin sobre a evolução das espécies.

É importante salientar aqui que embora a Inglaterra fosse o poder hegemônico econômico nas últimas décadas do século $\mathrm{XIX}$, algo que a literatura steampunk captura bem nas histórias ambientadas neste país, as particularidades históricas dos Estados Unidos no período imprimiram outros rumos a literatura norte-americana da época. A influência da quebra de tratados e expulsão de indígenas de suas terras, o conflito da guerra civil entre os estados do Norte e do Sul e o período da Reconstrução se faz sentir quando este passado é revisitado pelo retrofuturismo na expressão conhecida como cattlepunk. Refletindo a experiência do Velho Oeste americano e da expansão da fronteira sobre a psique norte-americana, o cattlepunk vai se alimentar da tradição literária estabelecida pelas dime novels para criar histórias de cowboys, colonizadores e exploradores em um contexto de alta tecnologia e crítica social. 
Falar ainda da Era Vitoriana, agora no plano doméstico das ilhas britânicas, é falar da Revolução Industrial iniciada na segunda metade do século XVIII. Privilegiada pela sua posição geográfica, que a mantinha relativamente distante dos conflitos no continente europeu, pela riqueza de recursos naturais, como o carvão que seria usado em indústrias e, por fim, pelo domínio de colônias que forneciam matéria prima e mercado consumidor (MCDOWALL, 1995, p.121-122), a Inglaterra foi palco de profundas mudanças que tornaram Londres uma das mais influentes capitais do mundo no século XIX, afetando todos os segmentos da população e os costumes do país. A invenção da máquina de fiação em 1764, por exemplo, eliminou a mão de obra de várias fiandeiras e mudou a indústria do algodão. Se antes este ofício era uma prática familiar, realizada no âmbito do lar, ele passou a ser realizada dentro das fábricas, onde os trabalhadores se submetiam as regras e a carga horária ditada pelos donos da indústria (MORTON, 1970, p.295). Em 1785 este quadro se agravou com a invenção da máquina de tecer, tornando a fabricação de tecidos uma atividade mais rápida, barata e lucrativa, mas trazendo como consequência o desemprego de milhares de trabalhadores, restando a eles e suas famílias a migração para a cidade. A cidade, por sua vez não conseguia oferecer condições dignas para estas pessoas, levando boa parte à pobreza e, por vezes, à marginalidade (ANTONIO, 2006, p.41).

É neste quadro de prosperidade econômica, dirigida por grandes indústrias e avanços tecnológicos sem paralelos, contrastando com aumento da degradação da vida urbana e a insatisfação das massas trabalhadoras com seus dirigentes que 
temos a base histórica que vem sendo usada pelos escritores de steampunk, encontrando paralelos no Brasil com o período conhecido como a Belle Époque.

A Belle Époque europeia foi o ponto alto de um período compreendido pelas últimas décadas do século XIX e primeiros anos do século XX identificado pela prosperidade econômica e estabilidade política resultante da expansão da indústria e das inovações tecnológicas aplicadas à sociedade. Esse ambiente permitiu que a classe média e alta desfrutasse de benefícios sem precedentes, gozando uma vida de extravagância e despreocupação. Bailes de máscaras, corrida de cavalos, partidas de polos e desfiles da última moda marcavam o compasso de vida dos abastados. As classes populares, entretanto, não apenas ficaram à margem dos efeitos positivos do progresso, mas também foram a sua principal vítima.

A Belle Époque desembarcou no Brasil via Portugal no fim do século XIX, acompanhando a influência francesa e inglesa sobre a antiga metrópole. Como salienta Jeffrey Needell sobre esse fato:

Para os brasileiros do século XIX, a Civilização era a França e a Inglaterra. Na verdade, desde a época colonial, os brasileiros seguiam o exemplo português e procuravam nos dois países o que houvesse de melhor. Sobretudo em matéria de tecnologia moderna (apesar de haver poucos interessados), ambos tinham muito a oferecer: A Inglaterra, através do exemplo e da experiência, e a França, através da experiência e do ensino. (NEEDELL, 1993, p.49)

Apesar da influência francesa e inglesa sobre o Brasil, via Portugal, poder ser rastreada até o princípio da formação do Brasil, foi a partir 
da implantação da República, e mais especificamente durante os primeiros anos do século $X X$ que ela se ampliou, impactando não apenas a vida cultural das grandes cidades brasileiras, mas também a sua própria estrutura social. Esse fato pôde ser constatado durante a chamada Primeira República (1889-1930), no período dos governos dos presidentes Campos Sales (1898-1902) e Rodrigues Alves (19021906) quando se buscou transformar o Rio de Janeiro, a capital federal do período, em uma Paris tropical.

Criada pelo jornalista Figueiredo Pimentel para o jornal Gazeta de Notícias a frase "O Rio civiliza-se" (GENS, 1994, p.I) se tornou a síntese das complexas alterações pelas quais o Rio de Janeiro experimentou durante o governo de Rodrigues Alves. A capital federal brasileira era objeto de desprezo por parte das elites por conta do seu estilo de vida colonial enquanto a meta era a construção de uma metrópole iluminada, progressista, voltada para o século $X X$ e pautada pela égide da Ciência e da tecnologia. Como salienta Aquino sobre este ponto:

Foi com este sentido que médicos e engenheiros, principais representantes da ciência no Brasil àquela altura, considerando-se os principais responsáveis pela salvação do povo brasileiro, articularam suas propostas de superação nacional, esboçando projetos de nação articulada ao conceito de progresso [e que] o discurso científico tornou-se um instrumento privilegiado para a legitimação de uma ordem social, não levando em conta direitos de cidadania de amplos setores da população [...]. (Apud MITTELMAN, 2003, p.11-12)

Dentre os "médicos e engenheiros" citados por Aquino, respectivamente Oswaldo Cruz e Pereira Passos foram os arautos 
do progresso na Belle Époque carioca. Suas ações se formalizaram na remoção de casas, casebres, prédios e cortiços que impediam a ampliação e a higienização da cidade e a retirada dos habitantes de tais locações sem direito a indenizações ou avisos prévios sobre a função e importância da vacinação. Logo, o povo começou a tratar as atividades da prefeitura como a "Ditadura Passos" (SEVCENKO, 1984, p.36). Configura-se desta forma, no Rio de Janeiro, capital do Brasil da Primeira República, o mesmo espaço urbano e contexto social semelhante ao de Londres, capital da Inglaterra vitoriana, no que se refere à visão dos abastados sobre as massas e do discurso racionalista hegemônico que viria a nutrir o surgimento do gênero ficção científica com Júlio Verne e H. G. Wells e que veio a ser explorado no século seguinte pela literatura steampunk. Mas, sendo assim, por que a ficção científica em seus momentos iniciais não se manifestou no Brasil da mesma forma que na Europa e nos Estados Unidos?

Há diferentes possibilidades levantadas pelos escritores e críticos da ficção científica nacional que apontam para a mesma conclusão. Segundo Bráulio Tavares, houve a ausência de dois fatores que inibiram a ascensão da ficção científica como um gênero já na Belle Époque carioca:

1) a existência de uma ou mais Grandes Obras que desencadeiam dezenas de imitações por anos a fio, ou 2) a existência de um grupo organizado de autores com objetivos semelhantes, que, [...] inscrevem uma tendência intelectual na história da literatura de seu país. (TAVARES, 1993, p.3)

Roberto de Sousa Causo, por sua vez, destaca em Ficção científica, fantasia e horror no Brasil (2003) a influência do cânone na formação e orientação de escritores nacionais: 
No Brasil, a prerrogativa cultural seduziu um grande número de escritores para as fileiras modernistas, enquanto a pequena população de pessoas realmente alfabetizadas e com o hábito de leitura não foi capaz de construir uma audiência que desse o apoio necessário aos escritores populares ou comerciais (supõe-se que os escritores elitistas se contentem apenas com glórias literárias). (CAUSO, 2003, p.234-235)

O que as considerações de Tavares e Causo apontam é que, apesar de termos apresentado no Brasil um sistema cultural semelhante ao da Inglaterra e da França, marcada pela Ciência como modeladoras da estrutura social e marginalizada das classes populares, a leitura dada a esse quadro pelos escritores de cada meio foi diferente. Se os romances de Júlio Verne e H. G. Wells traziam cientistas, engenheiros e professores como representantes da classe média que estavam desbravando a natureza e forjando uma nova nação, no Brasil a experiência com o progresso foi interpretada pelo olhar do ceticismo e pessimismo, construindo a imagem da Ciência como algo distante, invasor e por vezes de caráter sobrenatural (SILVA, 2008).

Se as duas possiblidades colocadas por Bráulio Tavares e Roberto de Sousa Causo partem da perspectiva de quem produzia literatura na época, um terceiro fator pode ser considerado, desta vez contemplando o lado de quem consumia essa mesma literatura (ou poderia consumir caso tivesse os meios para tanto). Na Inglaterra, por exemplo, havia uma massa trabalhadora que, ainda que fosse pobre, era letrada e consumia obras baratas voltadas para ela, como os penny dreadfuls vitorianos. Da mesma forma, as dime novels norte-americanas tinham como seu público 
principal a população alfabetizada dos grandes centros urbanos que conseguia comprar, por centavos, aventuras extravagantes ambientadas no Velho Oeste. A partir da última década do século XIX esse mesmo público passaria a se aventurar em outras regiões da Terra e em outros planetas nas recém-criadas revistas pulp. Mas, e no Brasil? Aqui, fatores como o fim tardio da escravidão, o analfabetismo e a baixa escolaridade das populações afastadas dos centros litorâneos impediram a formação de um público leitor grande o suficiente que permitisse a circulação de obras de fácil aquisição.

A despeito desse fato, seria um erro dizer que não houve manifestação de narrativas que podem ser vinculadas a ficção científica em nosso país. Já em 1857 o escritor Joaquim Manoel de Macedo publica o conto "O Fim do Mundo", sendo o precursor da temática apocalíptica em nossas letras (TAVARES, 2011, p.39). Em termos de narrativa longa, como explica Roberto de Sousa Causo (2003), O Doutor Benignus, de Augusto Emílio Zaluar, se constitui como um dos mais antigos exemplos do romance científico em nossas terras ao descrever uma hipotética expedição ao interior do Brasil. A obra de Zaluar reflete o lugar da influência da cultura francesa no Brasil do período tanto através das obras de Júlio Verne quanto da doutrina espírita de base kardecista. 0 Espiritismo também se faz presente como elemento constituinte de uma obra de ficção científica brasileira no romance $A$ Rainha do Ignoto (1899), de Emília Freitas, obra precursora da vertente das utopias feministas no país que descreve um reino governado por mulheres cuja localização é mantida em segredo na costa do Ceará. Mas será indubitavelmente na capital federal do início 
do século $X X$, o Rio de Janeiro, que iremos ver esta vertente do fantástico ganhar corpo por meio da contestação do discurso racionalista da Belle Époque.

Como demonstrado por Alexander Meireles da Silva (2008), a ficção científica foi assimilada pelo olhar de escritores da República Velha descompromissados com a divulgação das teorias científicas e dos avanços tecnológicos. Ao invés disso, surgiram narrativas que refletiam o distanciamento da população brasileira com a noção da Ciência como um produto da Razão incapaz de promover bem-estar social, algo efetivado através da Ciência Gótica e do Decadentismo em nossas letras.

Um subgênero do modo fantástico definido pela tensão entre o racional e o irracional, a ciência gótica, nas palavras de Bráulio Tavares, apresenta histórias que

têm um pé na ficção científica, utilizando muitos dos seus aparatos exteriores (cenários, personagens, artefatos), mas que se recusam a lidar com a lógica, a verossimilhança e a plausibilidade científica que os adeptos de ficção científica usam [...] Na ciência gótica, a parafernália tecnológica e a pseudoracionalização materialista estão a serviço de situações bizarras, grotescas, impressionantes. (TAVARES, 2003, p.15)

Exemplificado em obras como Frankenstein (1818), a ciência gótica foi uma das portas de entrada para a ficção científica no Brasil em obras como, apenas para citar dois casos dentre tantos outros, A esfinge (1906), e "A conversão" (1926), ${ }^{3}$ ambos do escritor Coelho Neto. Em A Esfinge, marcado por elementos decadentistas,

3 Apesar do ano de publicação, este conto, assim como outros do escritor, foram escritos nos primeiros anos do século vinte. 
um cientista místico une a cabeça de uma menina e o corpo de seu irmão, vítimas de um acidente de trânsito que os mutilaram, para criar um ser que, uma vez na forma adulta, provoca reações diversas nas pessoas ao seu redor pelo seu androginismo. Já no conto "A conversão", dois homens conversam sobre a conversão de um deles ao Espiritismo após ter presenciado a filha conversar com a neta falecida graças à utilização do telefone.

O Decadentismo, por sua vez, foi outra porta de entrada da ficção científica no Brasil. Expressando-se no Brasil em, dentre outras obras e autores, contos e crônicas do escritor e jornalista João do Rio como "A pressa de acabar" (1909) e "O dia de um homem em 1920" (1910) essa postura artística crítica da modernidade enxergava o progresso como algo alienador e desumanizador. Como João do Rio coloca em "A pressa de acabar":

O homem-cinematographo acorda pela manhã desejando acabar com várias coisas e deita-se à noite pretendendo acabar com outras tantas. [...] A pressa de acabar torna a vida um torvelinho macabro e é tão forte o seu domínio que muitos acabam com a vida ou com a razão apenas por não poder acabar depressa umas tantas coisas... (1971, p.152)

Diferente do ocorrido em grande parte na França e Inglaterra, portanto, a Ficção Científica em seus primeiros momentos não trouxe no Brasil uma promessa de futuro melhor, mas sim a advertência de um futuro pior.

Essa imagem negativa do racionalismo se agravaria na década de vinte quando, alinhadas com a literatura fantástica praticada na Europa em obras como Nós (1920), de Eugene Zamyatin, e Admirável 
mundo novo (1932), de Aldous Huxley, as distopias foram usadas no Brasil como veículos do pensamento eugenista vigente no período presentes nos debates sobre a composição do povo brasileiro. Esta presença se traduziu em romances como O Reino de Kiato (1922), de Rodolpho Theophilo, O Presidente negro ou o Choque das raças (1925), de Monteiro Lobato, e Sua Excia. a Presidente da República no ano 2500 (1929), de Adalzira Bittencourt (SILVA, 2008).

Nos anos trinta o imaginário futurista dos gadgets tecnológicos característicos das revistas pulp norte-americanas chegou ao Brasil por meio do escritor piauiense Berilo Neves (CAUSO, 2003, p.164). O sucesso de vendas das coletâneas de contos como A costela de Adão (1932) e Século XXI (1934) mostrou que o Brasil já demonstrava possuir um mercado consumidor apreciador dessa literatura a ponto inclusive de fomentar o surgimento de um imitador de Neves, o escritor Gomes Netto, autor de Novelas fantásticas (1934).

Seria de fato entre fins dos anos quarenta até fins dos anos sessenta que o jornalista, radialista e escritor paulista Jeronymo Monteiro estabeleceria uma sequência de obras de ficção científica que o levaram a ser considerado o 'pai' da FC Brasileira" (DUNBAR, 1976, p.17) ${ }^{4}$. Obras como Três meses no século 81 (1947), A Cidade Perdida (1948) e Fuga para parte alguma (1961) sinalizavam uma mudança da orientação da ficção científica brasileira, passando a abarcar, além das temáticas praticadas na Inglaterra e na França, a ficção científica norte-americana.

A obra de Monteiro anunciou uma nova fase desta forma literária no Brasil, que viria a se estabelecer na década de sessenta até meados dos anos setenta. Representada por escritores e 4 "father" of Brazilian. 
escritoras como, dentre outros nomes, Rubens Teixeira Scavone ( $O$ homem que viu o disco voador / 1958), Dinah Silveira de Queiroz (Eles herdarão a terra, 1960), Fausto Cunha (As noites marcianas, 1960) e Andre Carneiro (“Escuridão", 1963), esse grupo ficaria conhecido como "Geração GRD” (CUNHA, 1974, p.11). O nome é uma alusão ao trabalho desenvolvido pelo editor Gumercindo da Rocha Dórea, que acolheu a produção desses nomes na sua editora, dando origem ao que ficaria conhecido como a "Primeira Onda da Ficção Científica Brasileira" (BELL; MOLINA-GAVILÁN, 2003, p.19). Em essência, observou-se nesses escritores e escritoras o desenvolvimento de uma abordagem essencialmente humanista para a ficção científica brasileira, sem se pautar por preocupações excessivas com a fundamentação científica característica da expressão norte-americana e, por vezes, tangenciando com a New Wave inglesa, ${ }^{5}$ mantendo, contudo, distinções em relação a esta.

A Segunda Onda da Ficção Científica Brasileira (MATANGRANO; TAVARES, 2018, p.98) tem início nos anos oitenta e prosseguiu até o começo do século XXI, se caracterizando pela formação de uma base de leitores, escritores e escritoras que buscaram se articular em grupos, como o Clube de Leitores de Ficção Científica, e publicações na forma de fanzines variados, caso do Antares e Somnium, além de revistas ligadas a editoras, exemplificado na Isaac Asimov Magazine. Esse movimento buscava a disseminação de uma cultura de ficção científica no mercado editorial brasileiro e na própria cultura do país. Em termos de propostas, essa geração 5 O New Wave, iniciado na Inglaterra, marcou uma renovação da ficção científica nos anos sessenta e setenta do século vinte ao buscar experimentações temáticas e estruturais oriundas de outros campos do saber humano, como a Linguística, a Psicologia e a História, ampliando desta forma as Ciências até então normalmente utilizadas por esta vertente do Fantástico, tais como a Física e a Astronomia. 
exemplificada por nomes como, dentre muitos outros, Jorge Luiz Calife (Linha terminal, 1991), Roberto de Sousa Causo (A dança das sombras, 1999), Gerson Lodi-Ribeiro (Xochiquetzal: uma Princesa Asteca entre os Incas, 2009), Fábio Fernandes (Os dias da peste, 2009) e Simone Saueressig (A Máquina Fantabulástica, 1997) foi marcada pela influência do cyberpunk e a exploração de espaços e temáticas nacionais apontando para o amadurecimento da ficção científica no Brasil.

Finalmente, a Terceira Onda da Ficção Científica Brasileira marca o momento atual desta vertente do fantástico em nosso país se alinhando com o novo século (CAUSO, 2013, p.273). As redes sociais são os principais agentes neste quadro, possibilitando articulações de formação e contato com o público leitor (blogs e aplicativos como o wattpad), formas de publicação (financiamento coletivo) e divulgação (redes Facebook e Youtube). Observa-se a atividade de escritoras e escritores que trazem para esta literatura a diversidade de vozes presente em nossa sociedade multicultural, algo exemplificado no Afrofuturismo de Fábio Kabral e Lu AinZaila (SOUZA, 2019) e no Sertãopunk, um novo gênero criado em 2019 por Gabriele Diniz, Alec Silva e Alan de Sá para dar corpo a diversidade de olhares sobre o nordeste brasileiro em oposição ao que é enxergado como uma representação estereotipada da região praticada pela produção do sul e sudeste do Brasil (SÁ, 2019). Além disso, se percebe entre os pertencentes a Terceira Onda a frequente subversão dos limites da ficção científica com outras vertentes do fantástico, como a fantasia e o horror e a ascensão de novos gêneros e subgêneros como o new weird e, foco desse artigo, o steampunk. 
Na literatura, a estreia em obra nacional do steampunk ocorreu com a coletânea de contos Steampunk: histórias de um passado extraordinário (2009), publicada pela Tarja Editorial e organizada por Gianpaolo Celli (MATANGRANO; TAVARES, 2018, p.191). Refletindo o seu caráter de estreia, os contos refletiam a óbvia influência do steampunk norte-americano e inglês, assim como também do cyberpunk da década anterior, trazendo também contos ambientados no Brasil, caso de "Cidade Phantástica", de Romeu Martins, com favelas a vapor e gangues de capoeiristas ou "A flor de estrume", de Telma Vieira, que parte de Memórias Póstumas de Brás Cubas (1881) e Quincas Borba (1891), de Machado de Assis, em uma trama onde Cubas e Borba se unem para vender um emplastro no Rio de Janeiro de carruagens a vapor.

No ano seguinte, sinalizando o cenário positivo para a expansão do steampunk em língua portuguesa, assim como também a busca de um olhar local, a Editora Draco publicou Vaporpunk: Relatos steampunk publicados sob as ordens de Suas Majestades (2010), parceria Brasil e Portugal levada a cabo pelos organizadores Gerson Lodi-Ribeiro e Luís Filipe Silva, reunindo escritores dos dois países. O próprio título da coletânea, como explicam os organizadores no prefácio, já trazia a proposta do projeto: "desejamos mostrar noveletas cujos enredos digam respeito, direta ou indiretamente, às culturas brasileira e / ou portuguesa, exibindo o impacto social do avanço tecnológico precoce nas histórias dessas culturas." (LODI-RIBEIRO, SILVA, 2010, p.8). O sucesso do projeto levou a editora Draco a lançar em 2014 uma segunda coletânea de título Vaporpunk: Novos documentos de uma pitoresca época steampunk. Organizada por Fábio Fernandes e Romeu Martins, a publicação 
trouxe prefácio de S. J. Chambers, autora que, junto com Jeff Vandermeer, escreveu o Steampunk Bible (2011), obra norteamericana referência neste subgênero da ficção científica. Ainda neste campo, destaque para a coletânea Steampunk: Contos do Mundo do Vapor (2017), organizado por Gianpaolo Celli e Sérgio Pereira Couto, e publicado pela Dragonfly Editorial reunindo dez contos de escritores e escritoras nacionais.

Reflexos desse interesse do público brasileiro pelas narrativas punk também se fizeram presentes em outras publicações da Editora Draco, como em Dieselpunk: Arquivos confidenciais de uma bela época (2011) e Solarpunk: Histórias ecológicas e fantásticas em um futuro sustentável (2013), assim como também a obra Retrofuturismo (2013), da Tarja editorial, que, além de contemplar subgêneros conhecidos como o cyberpunk e o steampunk, trazia outras expressões na forma do stonepunk, bronzepunk, middlepunk, clockpunk, dieselpunk, nazipunk, atomicpunk e transistorpunk.

A segunda década do século vinte e um foi palco de uma diversificação das possibilidades do steampunk no Brasil em questões de gênero, sexo e fronteiras com outras vertentes do fantástico. No primeiro caso, a coletânea SteamPink (2011), publicada pela Editora Estronho e organizada por Tatiana Ruiz, reuniu contos steampunk escritos por mulheres. No campo do erotismo, Tatiana Ruiz e a Editora Ornitorrinco se reuniram para lançar Erótica Steampunk: Por Trás da Cortina de Vampiro (2013) e, subvertendo os limites entre a ficção científica e a fantasia, a Editora Estronho convidou Cândido Ruiz, Tatiana Ruiz e Marcelo Amado para organizarem a coletânea Deus Ex Machina: Anjos e Demônios na Era do Vapor (2013), trazendo seres do céu e do inferno como elementos centrais nas tramas. 
Na esfera dos romances nacionais que se nutriram do potencial steampunk, duas obras merecem posição pioneira, uma ligada ao subgênero da ficção científica da História Alternativa e outra da subcategoria do steampunk conhecida como steamfantasy. No primeiro caso, A mão que cria (2006), de Octavio Aragão e publicada pela Editora Mercuryo. A obra reúne diversas referências da literatura do século XIX e início do século XX com elementos da cultura pop em um mundo onde Júlio Verne se tornou Presidente da França, transformando o país em uma superpotência mundial. A história prosseguiu em A mão que pune - 1890 (2018), da Editora Caligari, com um prequel que amplia a ligação com o steampunk ao mesmo tempo em que insere o Brasil na história. No segundo caso, O Baronato de Shoah: A Canção do Silêncio (2011), de José Roberto Vieira, publicado pela editora Draco, vemos uma obra inserida na subcategoria do steamfantasy em que o mundo secundário característico da fantasia se une a ambientação steampunk. Em 2014 foi lançado a sequência A Máquina do Mundo (2014), publicada pela mesma editora. Outros romances steampunk escritos por brasileiros exploraram lugares e personagens consagrados do subgênero sem abordagem de questões nacionais, caso de Homens e Monstros: A Guerra Fria Vitoriana (2013), de Flavio Medeiros Jr., e Le Chevalier e a Exposição Universal (2015), de A. Z. Cordenonsi.

Mas seria ainda em 2014 que surgiria A Lição de Anatomia do Temível Dr. Louison, de Enéias Tavares, publicado pela Editora Casa da Palavra/Leya. Este foi o primeiro romance nacional ambientado no Brasil e que trouxe a releitura de personagens da Literatura Brasileira no enredo (MATANGRANO; TAVARES, 2018, p.196). Mais do que isso, esta obra ocupa lugar destaque ao refletir o 
amadurecimento e exploração plena do potencial do steampunk em nossa literatura fantástica. Esta percepção é confirmada na obra seguinte do escritor, desta vez contando com a parceria experiente de outros nomes ligados ao steampunk nacional como A. Z. Cordenonsi e Nikelen Witter, resultando no romance $A$ alcova da Morte (2017), publicado pela AVEC editora.

Refletindo as experimentações da literatura fantástica atual, A alcova da Morte é o resultado do trabalho colaborativo de seus autores. Cada personagem ficou sob a responsabilidade de um dos escritores culminando em uma obra dinâmica que revela a escrita de A. Z. Cordenonsi, Enéias Tavares e Nikelen Witter. Na trama, ambientada no Rio de Janeiro de 1892, um crime horrendo e misterioso ocorre na noite de inauguração da estátua do Corcovado, levando a agência de detetives Guanabara Real a se envolver na investigação. Gradativamente o trio de personagens desvela uma trama complexa de poderes terrenos e sobrenaturais que ameaçam não apenas a vida dos integrantes da agência, mas também podem causar destruição no país. Neste sentido, o grupo formado pela investigadora Maria Tereza Floresta, o engenheiro positivista negro Firmino Boaventura e o dândi místico de traços indígenas Remy Rudá exemplifica a proposta deste artigo de tomar o steampunk como símbolo da ficção científica brasileira no século XXI ao promover não apenas o diálogo com as raízes literárias de sua ascensão no Brasil na segunda metade do século XIX, mas também com as configurações desta expressão do modo fantástico no país. A composição do trio da agência de detetives promove o atravessamento das fronteiras desta obra steampunk para além das convenções da ficção científica, vindo a abraçar também o Romance de Detetives, o Decadentismo 
e o Horror. Tal fato demonstra como esta vertente do modo fantástico no Brasil consegue balancear tanto a situação atual da Ficção Científica no mundo, marcada pelo cruzamento de gêneros narrativos, como também incorporar questões tipicamente ligadas à nossa realidade do passado e presente. No caso de A alcova da morte em questão Enéias Tavares, A. Z. Cordenonsi e Nikelen Witter usam a ambientação retrofuturista para discutir, dentro da perspectiva do Brasil nos últimos anos do século XIX, temas ainda contundentes na sociedade brasileira.

Firmino Boaventura, por exemplo, personagem desenvolvido por A. Z. Cordenonsi, é um engenheiro negro em um Brasil que ainda não sabe bem como lidar com os recém libertos escravos de 1888. Essa situação atravessa toda a trama onde vemos o personagem atrair a atenção das pessoas tanto por ser negro na presença e lugares de brancos quanto pela mão mecânica que o engenheiro possui. Ao tomar uma condução para se encontrar com Maria Tereza ele percebe que:

O bilheteiro, que viajava em pé, com cara de quem gostaria de estar em qualquer outro vagão, desdobrava-se em explicações aos passageiros. Era o progresso, respondia ele, enquanto atentava ao rangido das engrenagens de sua mão mecânica e para a cor de sua pele. 0 dinheiro dele era tão bom quanto o de qualquer outro e o patrão o demitiria se não o recebesse. Era a Lei e a companhia teria problemas se não dispensasse um tratamento mínimo aos novos cidadãos. (TAVARES; WITTER; CONDENONSI, 2017, p.21-22)

Dentro da diegese de $A$ alcova da morte, Firmino é o representante vinculado a estética steampunk a partir da 
incorporação de partes artificiais ao seu corpo que, se por um lado, reforça a sua posição marginal na sociedade carioca, por outro promove uma vantagem em relação às demais pessoas pelas habilidades mecânicas do dispositivo. Será no engenheiro Firmino Boaventura que o leitor e a leitora encontrarão os goggles e maquinários identificados com esta expressão retrofuturista.

A personagem Maria Tereza Floresta, por sua vez, desenvolvida por Nikelen Witter, abarca a situação das mulheres pobres e crianças de rua levadas à prostituição por conta das profundas mudanças levadas a cabo pelas reformas urbanas que visavam transformar a capital federal em uma Paris tropical. Como somos informados sobre ela:

Havia quem lamentasse as mudanças do bairro. Tereza não. Lamentava as pessoas arrancadas dali para dar espaço aos novos salões elegantes à sombra dos Arcos da Carioca. Quanto aos bulevares, gostava deles. Vivera adolescente dormindo pelas ruas daquele lugar, antes das reformas e mudanças. Conhecera a fundo a sordidez da região. Se a tivessem chamado, ela teria pego em uma picareta e ajudado a demolir tudo com a força de seus braços (TAVARES; WITTER; CONDENONSI, 2017, p.75)

Representando uma mulher empoderada em pleno fim do século XIX, a personagem encabeça o elemento detetivesco da trama sendo a chefe da Agência Guanabara Real e usando sua experiência como um ser das ruas e ex-prostituta para desvendar os segredos de poderosos e clarear a sujeira das ruas.

Por fim, completando o trio, o personagem Remy Rudá, criado por Enéias Tavares, é o veículo por meio do qual enxergamos o 
espaço marginalizado dos cultos africanos, da homossexualidade e do Decadentismo dentro da Belle Époque carioca:

Boa parte dos estabelecimentos comerciais do Rio, especialmente os ditos familiares, não recebiam bem diversidades de qualquer estirpe. Remy, por exemplo, já passara várias vezes pela situação de ser convidado a se retirar, por seus trajes chamativos e sua postura invertida ofender os presentes (TAVARES; WITTER; CONDENONSI, 2017, p.65)

Descrito como um dândi místico de traços indígenas, Remy Rudá traz o elemento do Horror a $A$ alcova da morte a partir do alinhamento do Decadentismo com o misticismo e das práticas ritualísticas dos terreiros nas margens do Rio de Janeiro.

Percebe-se então que Enéias Tavares, Nikelen Witter e A. Z. Cordenonsi usam personagens marginais para construir uma obra steampunk que dialoga com diferentes convenções e estruturas. Em um segundo plano, essa abordagem de personagens marginais evidencia o lugar marginal da ciência em solo brasileiro.

Quanto ao diálogo com as bases da ficção científica no Brasil, conforme demonstrado anteriormente, a Era Vitoriana foi apropriada por escritores da década de oitenta na Inglaterra e nos Estados Unidos como período para o desenvolvimento de tramas onde, semelhante ao futuro imaginado pelo cyberpunk, o imenso avanço tecnológico em diversos campos não apenas se revelou ineficaz em resolver os problemas sociais de grande parte da população, mas também foi responsável por agravá-los. Para tanto, as obras steampunk resgatam o zeitgeist presente no imaginário das Aventuras Extraordinárias de Júlio Verne e dos Romances Científicos de H. G. Wells, dentre outras influências, para tanto celebrar a 
Ciência e o progresso (algo expresso nos maquinários a vapor e outros gadgets retrofuturistas) quanto criticá-los (representado no tratamento de questões sociais e econômicas ligadas aos marginalizados e minorias).

No Brasil, todavia, como vimos ao discorrer sobre o caminho percorrido pela ficção científica no Brasil a partir da segunda metade do século dezenove, a Ciência e o Progresso foram enxergados pelos escritores nacionais pelo víeis da contemplação, do sobrenatural e do desagregador, sem a utilização das suas perspectivas positivas. O que obras como A Lição de Anatomia do Temível Dr. Louison, A Alcova da Morte e algumas das coletâneas de contos citadas aqui que ambientam o steampunk em solo brasileiro abordando temas nacionais fazem é revisitar a Primeira República e, mais especificamente, a Belle Époque para, finalmente, estabelecer diálogo com o imaginário científico da época e explorá-lo como matéria prima de narrativas fantásticas. Nesta leitura, portanto, escritoras e escritores nacionais do steampunk preenchem, no presente, uma lacuna deixada aberta pelos escritores brasileiros do início do século $X X$.

Esta ação empreendida pelas obras brasileiras de steampunk, em especial aqui A alcova da morte que tomam o passado nacional em seus enredos, acaba por indiretamente tocar na problemática a respeito do lugar da ficção científica no Brasil. Remetendo as opiniões de Bráulio Tavares (1993) e Roberto de Sousa Causo (2003), já expostas aqui, sobre as possíveis razões da falta de uma cultura de Ficção Científica no país semelhante à observada na América, podemos considerar que, mais uma vez, a falta de uma visão otimista no início do século XX por parte de escritores brasileiros que demonstrasse a importância 
e relevância da aplicação da Ciência na sociedade acarretou na sua pouca valorização enquanto elemento capaz de capturar a imaginação de outros escritores e escritoras e instigar a imaginação do público leitor. O que o steampunk promove, então, é uma ressignificação do lugar do saber científico em nossa sociedade, chamando a atenção de leitores e leitoras brasileiras para nosso passado na área com figuras como Santos Dumont, Padre Landell de Moura, Oswaldo Cruz e outros nomes cujos feitos fornecem matéria para narrativas fantásticas. Neste sentido, pelos argumentos apresentados, o steampunk brasileiro difere do que os críticos Jean-Jacques Girardot e Fabrice Méreste (2006) consideram como a principal característica desse subgênero da ficção científica, que é o de promover uma reciclagem ao recuperar elementos do passado e atribuir-lhes nova utilização. O que está presente no território do steampunk brasileiro nesta segunda década do século vinte e um, de fato, é a utilização inédita desse passado ao lado de outras influências ligadas ao imaginário.

"O movimento literário está crescendo rápido, e ouso dizer que os próximos dois ou três anos vão ver o nascimento de um verdadeiro gênero literário steampunk brasileiro" (FERNANDES Apud CHAMBERS, 2014, p.12). As palavras proféticas do escritor Fábio Fernandes em 2014 para a editora de Steampunk Bible se concretizaram. Como foi analisado ao longo deste artigo, no qual foi apresentado um breve panorama da ficção científica nacional a partir de suas raízes na segunda metade do século dezenove, passando pelas diferentes ondas desta vertente do fantástico no país, chegando até os dias de hoje com o romance $A$ alcova da morte, o steampunk é o herdeiro de uma tradição que reestabelece o diálogo com o passado da ficção científica no Brasil, promovendo o 
equilíbrio entre valorização e crítica do pensamento científico. Obras do escritor e ilustrador Gabriel Billy, como o romance Vera Cruz: Sonhos e pesadelos (2018), em que o folclore brasileiro é revisitado pelas lentes do steampunk e Ignotos, webcomics mostrando um grupo de heróis formados por personagens da literatura fantástica brasileira da República Velha, além de projetos transmidiáticos encabeçados pelo Conselho Steampunk e pelo Orc Studio, levando narrativas steampunk para o universo das web séries e história em quadrinhos, vão nesse caminho, mostrando que a ficção científica brasileira vai buscar em seu passado rico de potencial narrativo a matéria prima para projetar o seu futuro.

\section{REFERÊNCIAS}

ANTONIO, Rodrigo (2006). "A religião do progresso". In: FUSER, Igor (Org.). O leão britânico. São Paulo: Duetto Editorial. (História Viva - Grandes Temas, 16). p.38-43. BELL, Andrea L.; MOLINA-GAVILÁN, Yolanda. (Eds.) (2003). Cosmos Latinos: An Anthology of Science Fiction from Latin America and Spain. Middleton, CT: Wesleyan University Press.

CAREY, John (1993). Os intelectuais e as massas: orgulho e preconceito entre a intelligentsia literária, 1880-1939. Ronaldo Kyrmse (Trad.). São Paulo: Ars Poética. CARVALHO, J. M. de (1987). Os bestializados: O Rio de Janeiro e a república que não foi. São Paulo: Companhia das Letras.

CAUSO, Roberto de Souza (2003). Ficção científica, fantasia e horror no Brasil: 1875-1950. Belo Horizonte: Editora UFMG.

(2013). Ondas na praia de um mundo sombrio: New Wave e Cyberpunk no Brasil. (Tese - Doutorado em Estudos Linguísticos em Inglês) $315 f$. Universidade de São Paulo, São Paulo. In https://goo.gl/sPb9vZ Acesso em 2.Nov.2019.

(2015). "Esboço de uma história da crítica de ficção científica no Brasil".

In: SUPPIA, Alfredo. (Org.). Cartografia para a ficção científica mundial: cinema e literatura. São Paulo: Alameda. p.173-207. 
CESERANI, Remo (2006). O fantástico. Curitiba: Editora UFPR.

CHAMBERS, S. J. (2014) "Prefácio". In: FERNANDES, Fábio; MARTINS, Romeu. Vaporpunk: Novos documentos de uma pitoresca época steampunk. São Paulo: Draco. p.10-13.

CLUTE, John (1995). Science Fiction: The Illustrated Encyclopedia. London: Dorling Kindersley.

CLUTE, John; NICHOLLS, Peter (1995). "Steampunk". In: - The Encyclopedia of Science Fiction. New York: St. Martin's Griffin. p.1161.

CUNHA, Fausto (1974). "A ficção científica no Brasil". In: ALLEN, L. David. No mundo da ficção científica. Antonio Alexandre Faccioli e Gregório Pelegi Toloy (Trad.). São Paulo: Summus Editorial. p.5-20.

DUNBAR, David Lincoln (1976). Unique Motifs in Brazilian Science Fiction. (Dissertation - Doctor of Philosophy). The University of Arizona, Arizona. In http://hdl.handle.net/10150/289377 Acesso em 2.Nov.2019.

FERNANDES, Fábio (2006). A construção do imaginário cyber: William Gibson, criador da cibercultura. São Paulo: Editora Anhembi Morumbi.

GENS, Rosa Maria de Carvalho (1994). "Os tempos mudaram, meu caro...". In: RIO, João do. O momento literário. Rio de Janeiro: Fundação Biblioteca Nacional.

GIRARDOT, Jean-Jacques; MÉRESTE, Fabrice (2006). “Le steampunk: une machine littéraire à recycler le passé". Revue Cycnos, 22(1). Nice (França): Université de Nice. In https://goo.gl/2W5rLG Acesso em 7.Out.2019.

HEARSCMANN, Micael Maiolino, PEGORARO, Everly, FERNANDES, Cíntia SanMartin Fernandes (2013). "Steampunk e retrofuturismo: reflexos de inquietações sociotemporais contemporâneas". Comunicação, mídia e consumo, 10(28). São Paulo: ESPM, Mai./Ago, 209-228. In http://bit.ly/2PFdxO2 Acesso em 2.Mar.2020.

HOBSBAWM, J. Eric (1988). A Era Dos Impérios: 1875-1914. Sieni Maria Campos e Yolanda Steidel de Toledo (Trad.). Rio de Janeiro: Paz e Terra.

LODI-RIBEIRO, Gerson, SILVA, Luís Filipe (2010). "Prefácio". In (Orgs.). Vaporpunk: Relatos steampunk publicados sob as ordens de Suas Majestades. São Paulo: Draco. p.6-9. 
MACARTNEY, George (2006). "An Account of Ireland in 1773 by a Late Chief Secretary of that Kingdom". In: KENNY, Kevin. Ireland and the British Empire. Oxford: Oxford University Press.

MATANGRANO, Bruno Anselmi; TAVARES, Enéias (2018). Fantástico brasileiro: O insólito literário do Romantismo ao Fantasismo. Curitiba, PR: Arte \& Letras.

MCDOWALL, David (1995). An Illustrated History of Britain. Essex: Longman.

MITTELMAN, Tânia (2003). A revolta da vacina: vacinando contra a varíola e contra o povo. Rio de Janeiro: Editora Ciência Moderna.

MORTON, A. L. (1970). A história do povo inglês. José Laurênio de Melo (Trad.). Rio de Janeiro: Civilização Brasileira.

MOYLAN, Tom (2000). Scraps of the Untainted Sky. Colorado: Westview Press.

NEEDELL, Jeffrey D. (1993). Belle Epoque Tropical: Sociedade e cultura de elite no Rio de Janeiro na virada do século. Celso Nogueira (Trad.). São Paulo: Companhia das Letras.

NEVINS, Jess (2008). "Introduction": The 19th-Century Roots of Steampunk. In: VANDERMEER, Ann \& VANDERMEER, Jeff (Orgs). Steampunk. San Francisco: Tachyon. p.3-11.

PEGORARO, Éverly (2014). "Retrofuturismo e experiência urbana: o steampunk no Brasil". XII Congresso De La Asociación Latinoamericana De Investigadores De La Comunicación (ALAIC), Lima, Peru. In https://goo.gl/9R2rGZ Acesso em 20.Out. 2019.

RIO, João (1971). "A pressa de acabar". In: MARTINS, Luís. João do Rio: uma antologia. Rio de Janeiro: Instituto Nacional do Livro.

ROBERTS, Adam (2018). A verdadeira história da ficção científica: Do preconceito à conquista das massas. Mário Molina (Trad.). São Paulo: Seoman.

SÁ, Alan de (2019). "Por que fazer o Nordeste Sertãopunk?". Medium. In https://medium.com/alan-de-s\%C3\%A1/sertaopunk-c0e0015a13ea Acesso em 02.Mar.2020.

SEVCENKO, Nicolau (1984). A revolta da vacina: mentes insanas em corpos rebeldes. São Paulo: Editora Brasiliense.

SILVA, Alexander Meireles da Silva (2005). Literatura inglesa para brasileiros: literatura e cultura inglesa para estudantes brasileiros. 2.ed. Rio de Janeiro: Editora Ciência Moderna. 
(2008) O admirável mundo novo da República Velha: O nascimento da ficção científica brasileira no começo do século XX. (Tese - Doutorado em Literatura Comparada). Universidade Federal do Rio de Janeiro, Rio de Janeiro. In https://goo.gl/Au75GN Acesso em 02.Nov. 2019.

SOUZA, Waldson Gomes de (2019). Afrofuturismo: O futuro ancestral na literatura brasileira contemporânea. (Dissertação - Mestrado em Literatura). Universidade de Brasília, Brasília. In https://repositorio.unb.br/handle/10482/35472 Acesso em 02.Mar.2020.

STRAW, W. "Scenes and Sensibilities" (2006). E-compós, (6), Ago, Brasília. In https://www.e-compos.org.br/e-compos/article/view/83/83 Acesso em: 01.Mar.2020.

TAVARES, Bráulio (Org.) (2003). Páginas de sombra: contos fantásticos brasileiros. Rio de Janeiro: Casa da palavra. (2011). Páginas do Futuro: contos brasileiros de ficção científica. Rio de Janeiro: Casa da palavra.

TAVARES, Enéias; WITTER, Nikelen; CORDENONSI, A. Z. (2017). A alcova da morte. Porto Alegre: AVEC.

TAVARES, Enéias; MATANGRANO, Bruno Anselmi (2018). Fantástico brasileiro: O insólito literário do Romantismo ao Fantasismo. Curitiba, PR: Arte \& Letras.

ZACARIAS, Gabriel Ferreira (2006). "Orgulho e desigualdade". In: FUSER, Igor (Ed.). O leão britânico. São Paulo: Duetto Editorial. (História Viva - Grandes Temas, 16). p.52-56. 